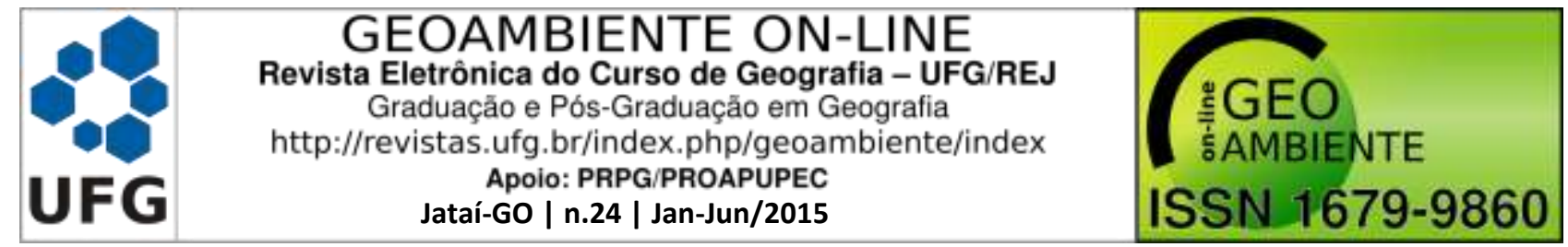

\section{PRODUÇÃO DE SEDIMENTOS E ASSOREAMENTO EM RESERVATÓRIO NO SEMIÁRIDO: O CASO DO AÇUDE MARENGO, CEARÁ}

José Wellington Batista Lopes ${ }^{1}$, José Ribeiro de Araújo Neto ${ }^{1}$, Everton Alves Rodrigues Pinheiro $^{2}$

(1 - Universidade Federal do Ceará - UFC, doutorando em Engenharia Agrícola, wellingtonjwl@gmail.com, juniorifcelabas@gmail.com; 2 - Universidade de São Paulo ESALQ/USP, doutorando em Engenharia de Sistemas Agrícolas, evertonvest@ yahoo.com.br)

Resumo: $\mathrm{O}$ assoreamento de reservatórios é um processo que merece bastante atenção no semiárido cearense, visto que, o abastecimento hídrico dessa região dar-se basicamente das águas superficiais. No presente artigo propõe-se uma aplicação do modelo USLE associado ao SIG para estimativa da distribuição espacial da erosão, bem como, a quantificação do assoreamento em um reservatório de águas superficiais no estado do Ceará, o açude Marengo localizado no município de Madalena. A bacia hidrográfica possui uma área de 74,6 km², sendo a capacidade de armazenamento do reservatório de $18,5 \mathrm{hm}^{3}$. O levantamento batimétrico foi utilizado a fim de verificar o grau de aproximação dos resultados simulados aos dados medidos. Portanto, foram simulados outros três cenários: i) 60 anos após a construção, sendo esse o cenário utilizado na aferição do modelo; ii) 100 anos e iii) 200 anos. A distribuição da perda de solo em quase $70 \%$ da bacia do reservatório apresenta valor menor que $50 \mathrm{t} \mathrm{ha}^{-1}$ ano $^{-1}$, sendo considerada como grau moderado de erosão. A produção de sedimento média para a bacia foi de $5,22 \mathrm{tha}^{-1} \mathrm{ano}^{-1}$. O volume assoreado médio anual foi da ordem de $0,028 \mathrm{hm}^{3}$ ano $^{-1}$ resultando em uma taxa moderada de assoreamento da ordem de $0,15 \%$ ao ano. Verificou-se que curva cota- volume medida a partir da batimetria, está próxima à curva estimada pelo modelo no mesmo período de tempo, mostrando a robustez do modelo USLE+SIG na estimativa do assoreamento.

Palavras-chave: Assoreamento. Erosão. Semiárido. SIG.

\section{SEDIMENT YIELD AND RESERVOIR SILTATION IN SEMIARID REGION: THE CASE OF THE MARENGO RESERVOIR, FEDERAL STATE OF CEARA}

Abstract: Reservoir siltation is a process which influences the availability of drinking water in semiarid regions, in special in federal state of Ceara, where the water supply is primarily

Artigo recebido para publicação em 11 de Fevereiro de 2015

Artigo aprovado para publicação em 21 de Junho de 2015 


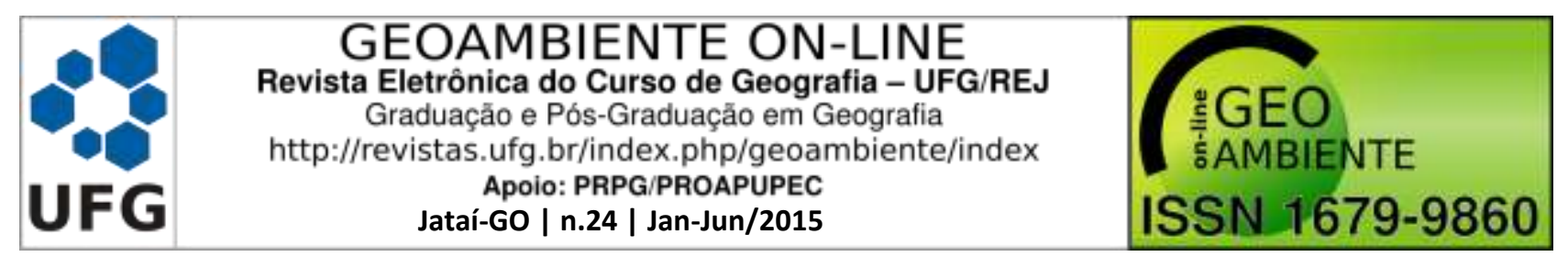

from surface sources. In this paper we propose an application of the USLE model coupled with GIS tool to estimate the spatial distribution of erosion, as well as the quantification of the reservoir siltation in the dam Marengo, Madalena municipality. The area of the catchment is $74.6 \mathrm{~km}^{2}$, and the reservoir storage capacity is $18.5 \mathrm{hm}^{3}$. Bathymetric survey was used to compare the simulated and measured data. Therefore, three other scenarios were simulated: i) 60 years after construction, which is the scenario used in the measurement model, ii) 100 years and iii) 200 years. The distribution of soil loss in almost $70 \%$ of the catchment is lesser than $50 \mathrm{tha}^{-1} \mathrm{yr}^{-1}$, which is considered a moderate degree of erosion. The average of sediment yield in the whole catchment was $5.22 \mathrm{t} \mathrm{ha}^{-1} \mathrm{yr}^{-1}$. The average of annual siltation volume was approximately $0.028 \mathrm{hm}^{3} \mathrm{yr}^{-1}$, resulting in a moderate rate of sedimentation of the order of $0.15 \%$ per year. The elevation-volume curve measured was observed to be similar to the simulated one performed by the model. This shows the robustness of the USLE model coupled with a GIS tool in estimating siltation processes.

Keywords: Erosion. GIS. Reservoir sedimentation. Semiarid environment.

\section{PRODUCCIÓN DE SEDIMENTOS Y SEDIMENTACIÓN EN EMBALSE EN EL SEMIÁRIDO: EL CASO DE LA REPRESA MARENGO, CEARÁ}

Resumen: La sedimentación en embalses es un proceso que merece bastante atención en el semiárido del Ceará, visto que, el abastecimiento hídrico de esa región darse básicamente por aguas superficiales. En el presente artículo se propone una aplicación del modelo USLE asociado al SIG para estimativa de la distribución espacial de la erosión, así como, la cuantificación de la sedimentación en un embalse en el estado de Ceará, la represa Marengo, localizada en el municipio de Madalena. La cuenca hidrográfica posee un área de $74,6 \mathrm{~km}^{2}$, siendo que la capacidad de almacenamiento es de $18,5 \mathrm{hm}^{3}$. El levantamiento batimétrico fue utilizado para que se verifique el grado de aproximación de los resultados a los datos medidos. Por lo tanto, fueron simulados tres escenarios: i) 60 años después de la construcción, siendo ese escenario utilizado en la evaluación del modelo; ii) 100 años y iii) 200 años. La distribución de la pérdida del suelo en casi $70 \%$ de la cuenca del depósito presenta valor menor que $50 \mathrm{t} \mathrm{ha}^{-1} \mathrm{año}^{-1}$, siendo considerada como grado moderado de erosión. La producción de sedimentos media para la bacía fue de 5, 22 t ha- ${ }^{1}$ año- ${ }^{1}$. El volumen enarenado medio anual fue del orden de $0,15 \%$ al año. Se comprobó que la curva cota - volumen medida a partir de la batimetría - está próxima a la curva estimada por el modelo en el mismo período de tiempo, mostrando la robustez del modelo USLE+SIG en la estimativa de la colmatación de sedimentos. 


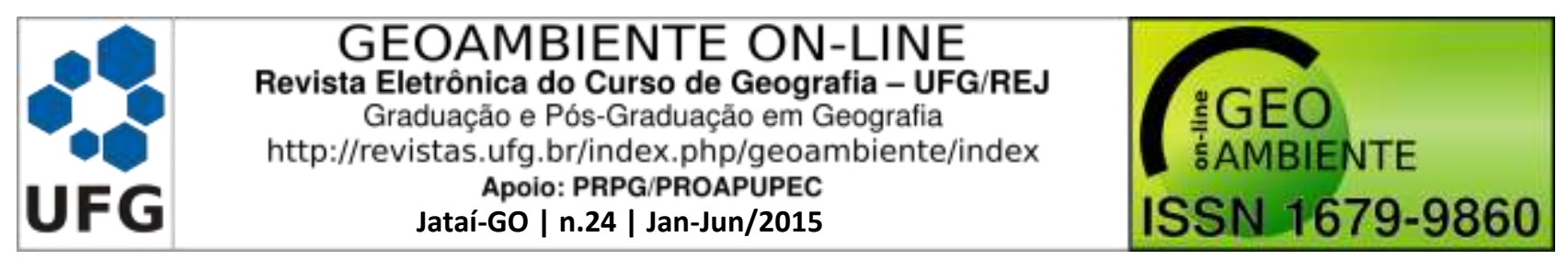

Palabras-clave: Sedimentación. Erosión. Semiárido. SIG.

\section{Introdução}

A pequena açudagem associada com a construção de reservatórios estratégicos se faz a principal fonte de distribuição dos recursos hídricos no semiárido brasileiro. De acordo com Araújo et al. (2005) mais de 90\% da água demandada pelo estado do Ceará é suprida por meio de barragens. No entanto, os reservatórios no semiárido conseguem regularizar apenas $40 \%$ da vazão afluente, "perdendo" $60 \%$ entre evaporação e extravasamento. Com o assoreamento, a tendência geral é de aumento dessas perdas por evaporação (uma vez que as relações cota-área-volume sofrem alterações) e das perdas por extravasamento (uma vez que há redução da capacidade acumulativa do reservatório) (ARAÚJO, 2003).

Os problemas trazidos pelo assoreamento e a deposição de sedimento no reservatório dizem respeito principalmente à redução do volume útil do reservatório, que irá interferir no uso para o qual foi construído, como: geração de energia, abastecimento público ou industrial, irrigação, contenção de enchentes, dentre outros. Pode-se ainda destacar problemas operacionais vinculados a este processo, como: abrasão de componentes - tubulações, pás de turbina, sistemas hidráulicos; problemas mecânicos nas manobras das eclusas e comportas; dificuldade ou impedimento da captação pela estrutura de tomada d'água; afogamento dos locais de desova, alimentação e abrigo dos peixes; formação de bancos de areia diminuindo o calado para a navegação, além de afetar a segurança da barragem (MAIA; VILLELA, 2006).

$\mathrm{O}$ aceleramento dos processos erosivos e de perdas de solo são um dos principais processos responsabilizados pelo comprometimento dos recursos hídricos e causadores do assoreamento nos reservatórios do semiárido cearense. A magnitude deste fenômeno tem sido considerada uma ameaça à própria existência da humanidade. Esta ameaça tem contribuído para a urgência de se quantificar e controlar, de forma racional, as causas do processo erosivo (ALBURQUERQUE et al., 2005).

Diversos modelos ou equações têm sido empregados na estimativa da perda de solo em bacias hidrográficas, sendo o uso da Equação Universal de Perda de Solos (Universal Soil Loss Equation - USLE), proposta por Wischmeier e Smith (1978), um dos métodos mais citados na literatura (MEDEIROS et al., 2010). A USLE é uma equação empírica para estimar a erosão potencial, em virtude de fatores que representam as características climáticas, propriedades dos solos, topografia e práticas de uso e manejo dos solos (IRVEM et al., 2007). 


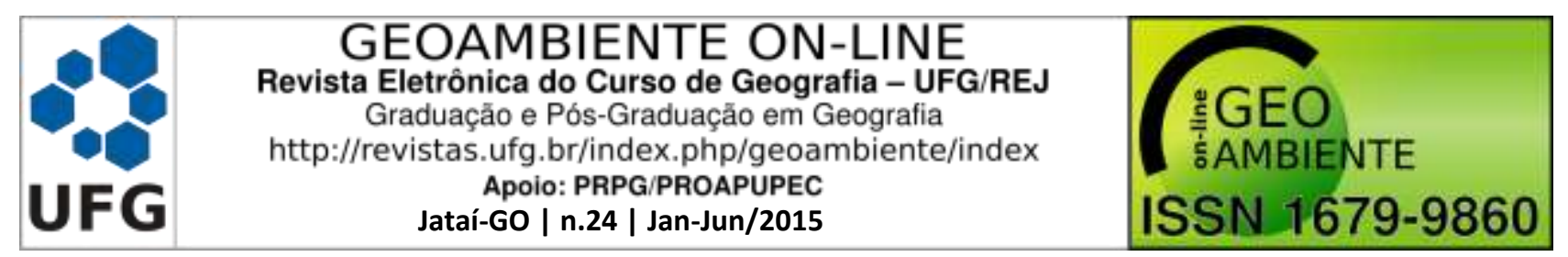

A aplicação de modelos quantitativos de estimativa da distribuição da perda de solo foi fortemente facilitada com o desenvolvimento dos Sistemas de Informações Geográficas (SIG). Sendo assim, a Equação Universal de Perdas de Solos (USLE) quando espacializada por meio do SIG, permite a análise da distribuição da perda de solo por erosão laminar além da contextualização dos resultados obtidos em função do uso e ocupação das terras (LOPES et $a l ., 2011)$. Como exemplo deste tipo de aplicação do modelo USLE associado ao SIG pode-se citar as estimativas da perda de solo realizadas por Chair (2005), Farinasso et al. (2006), Irvem et al. (2007), Toledo et al. (2010), Serio et al. (2008), Medeiros et al. (2010) e Lopes et al. (2011).

Nesse contexto, esse estudo foi conduzido com o objetivo de aplicar o modelo USLE associado ao SIG para estimativa da distribuição espacial da perda de solo na bacia do açude Marengo, bem como, quantificar o assoreamento do reservatório para o cenário atual e simulação de cenários futuros.

\section{Material e métodos}

\subsection{Descrição da área de estudo}

A área foco do estudo foi a bacia hidrográfica do açude Marengo $\left(74,6 \mathrm{~km}^{2}\right)$, no Estado do Ceará, a qual é controlada em seu exutório pelo reservatório Marengo localizado no município de Madalena (capacidade de $18,5 \mathrm{hm}^{3}$, ampliado para a capacidade atual na década de 50) (Figura 1). Esse constitui a principal fonte de abastecimento do Assentamento 25 de maio e, responsável pela perenização de um trecho do rio a jusante da barragem. O clima é tropical semiárido, do tipo BS de acordo com a classificação de Köppen, com precipitação média anual da ordem de $580 \mathrm{~mm}$ (média de 25 anos). A elevação da bacia varia de 250 a 370 metros acima do nível do mar. O solo presente na bacia é do tipo Luvissolo (Bruno não cálcico). A vegetação predominante é a Caatinga arbustiva densa.

\subsection{Levantamento Batimétrico}

O levantamento batimétrico foi realizado para o açude Marengo no ano de 2011, com o objetivo de determinar a nova capacidade de armazenamento do reservatório 60 anos após a sua construção, bem como a nova curva cota - volume. Para tanto, foi utilizado um GPS para o levantamento das coordenadas (x,y) dos pontos de contorno, margens dos açudes e seções batimétricas, assim como, um profundímetro para medida das profundidades ao longo de diversas seções batimétricas. Foram coletados mais de 3.000 pontos (profundidades) ao longo 


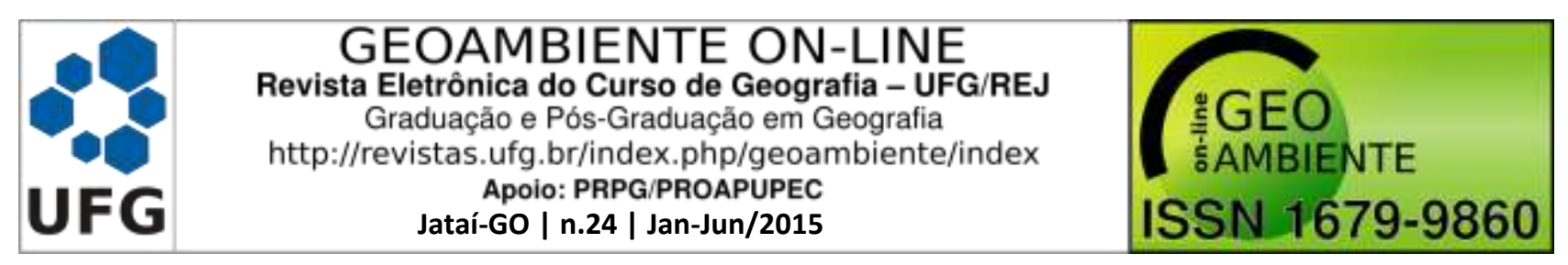

da bacia hidráulica do Marengo, resultando em uma densidade de pontos coletados de 11 pontos/ha.

Figura 01: Localização da bacia hidrográfica do açude Marengo, Ceará, Brasil.
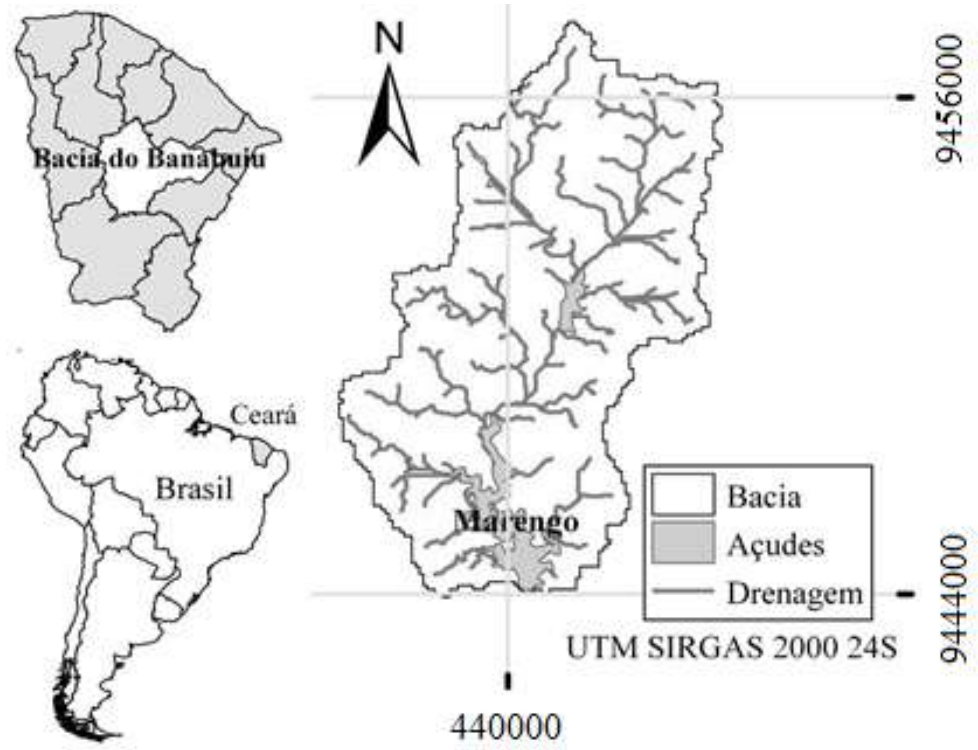

\subsection{Estimativa da Perda de Solo (USLE - Universal Soil Loss Equation)}

Dentre os modelos matemáticos utilizados para estimar a erosão hídrica por unidade de área e tempo, a Equação Universal de Perda de Solo (USLE) é uma das mais usadas. A USLE (Eq. 1) foi determinada analisando-se dados de escoamento superficial em mais de 10.000 parcelas experimentais, sob condições de chuva, natural e simulada, e de distintas características de clima, solo, relevo e cultivo nos Estados Unidos (IRVEM, et al., 2007).

$E_{L}=R_{i j} \cdot K_{i} \cdot L S_{i} \cdot C P_{i j}$

em que: $E_{L}=$ erosão localizada $\left(\mathrm{t} \mathrm{ha}^{-1}\right) ; R_{i j}=$ fator de erosividade da chuva em MJ mm ha ${ }^{1} \mathrm{~h}^{-1} ; K_{i}=$ fator de erodibilidade do solo em $\mathrm{t} \mathrm{h} \mathrm{MJ}^{-1} \mathrm{~mm}^{-1} ; L S_{i}=$ fator topográfico adimensional - função dos fatores LR (comprimento de rampa) e $S_{d}$ (declividade); $C$ = fator adimensional que expressa o uso e manejo do solo e características da cultura; $P_{i j}=$ fator adimensional que reflete o uso de práticas conservacionistas.

\subsection{Fator erosividade da chuva (Fator $R$ )}

Para a obtenção do fator de erosividade (R), utilizou-se a metodologia proposta por Bertoni e Lombardi Neto (1993), a qual é expressa pela Eq. 2. Os dados relativos aos totais 


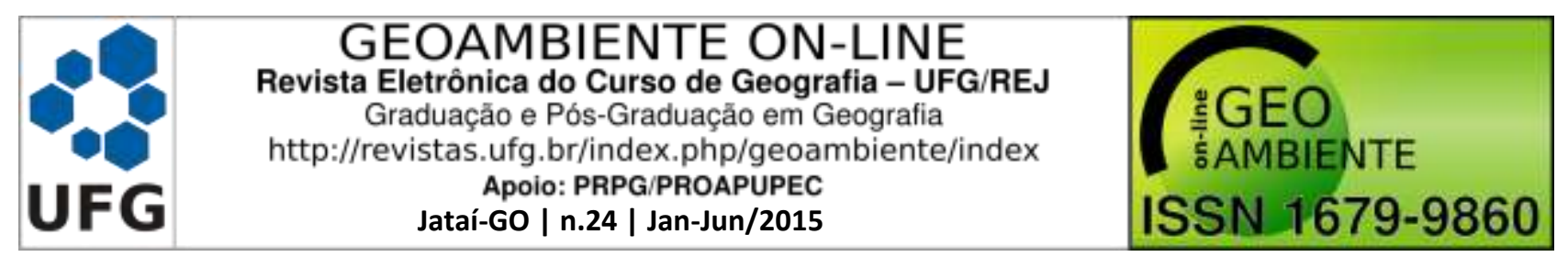

mensais e anuais de precipitação, necessários para a estimativa da erosividade, foram adquiridos junto a Fundação Cearense de Meteorologia do Estado do Ceará (FUNCEME).

$R_{j}=67,355 \cdot\left(\frac{P_{m}^{2}}{P_{a}}\right)^{0,85}$

em que: $R_{j}=$ fator de erosividade da chuva em MJ $\mathrm{mm} \mathrm{ha}^{-1} \mathrm{~h}^{-1} ; P_{m}=$ representa a precipitação total média mensal $(\mathrm{mm}) ; P_{a}=$ representa a precipitação total média anual $(\mathrm{mm})$.

Para determinação de apenas um único fator de erosividade mensal ao longo da série (1988-2011), para cada posto pluviométrico, foi calculada a média pluviométrica mensal entre os três postos existentes na área e posteriormente efetuado o cálculo do fator R. Utilizou-se a interpolação pelo método da Krigagem (TOLEDO et al., 2010; LOPES et al., 2011)no ArcMap 9.3 na obtenção do mapa do fator erosividade.

\subsection{Fator erodibilidade do solo $(K)$}

Os valores de erodibilidade do solo foram estabelecidos por Silva (1978), fundamentados em estudo de campo, laboratório e análise de regressão. Os referidos valores de $\mathrm{K}$ foram associados às respectivas classes no mapa de solos da bacia em estudo. Utilizando as funções do SIG, gerou-se um raster com o fator de erodibilidade da bacia estudada e através destes valores, determinou-se um mapa temático da erodibilidade dos solos para a área de estudo.

\subsection{Fator Topográfico $(L S)$}

O mapa temático do fator topográfico LS, foi gerado empregando-se os dados do Modelo Numérico do Terreno fornecidos pelo Shuttle Radar Topography Mission (SRTM) da NASA. Com isso o fator LS foi obtido através da Eq. 3, proposta por Chair (2005).

$L S=1,6 \cdot\left(\frac{F A C * R E S}{22,1}\right)^{0,6} \cdot\left(\frac{\operatorname{sen}(\operatorname{decli} \cdot 0,01745)}{0,09}\right)^{1,3}$

em que: $F A C=$ corresponde ao acúmulo de fluxo de escoamento superficial; $R e s=$ representa a base do SRTM com uma resolução espacial de $92 \mathrm{~m}$; decli = representa a declividade das células (gerado no ArcMap).

\subsection{Fatores Cobertura do Solo e Práticas Conservacionistas (C e P)}




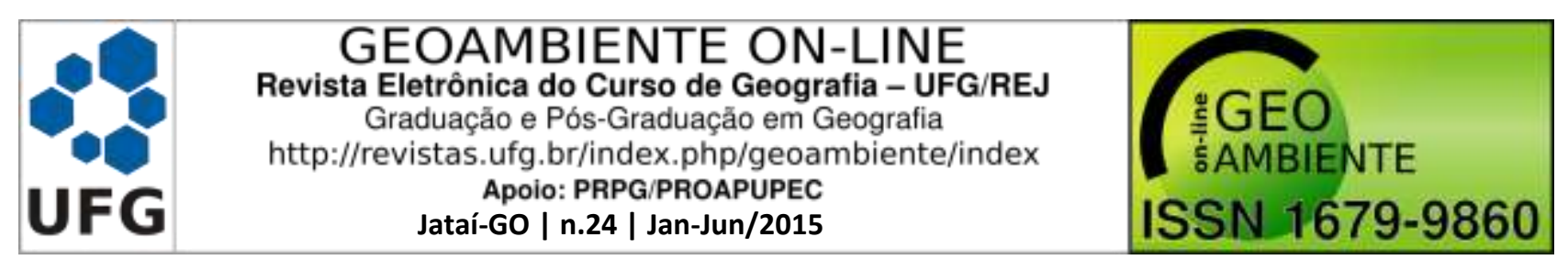

Para a determinação do fator C, utilizou-se uma imagem Landsat 5 sensor TM de 18 de agosto de 2007 de órbita e ponto 217/63. Para se obter a classificação da imagem utilizouse a composição das bandas 4-3-2. A classificação foi feita com o emprego de um algoritmo de classificação supervisionada (software ENVI 4.3), para tal, definiu-se quatro classes dentro da bacia: água, vegetação rala, vegetação densa e solo exposto.

Uma vez classificada a imagem da área, foi calculado o percentual de cada classe e atribuído o valor correspondente do fator C recomendado por Fujihara (2002), ou seja, água $(0,0)$; vegetação rala $(0,25)$; vegetação densa $(0,01)$ e solo exposto $(1,0)$. Considerou-se que não existia a adoção das práticas conservacionistas de controle à erosão sendo o fator prática conservacionista P igual a 1.

\subsection{Classificação da Erosão Localizada $\left(E_{L}\right)$}

Visando avaliar o enquadramento dos resultados obtidos de perda de solo com susceptibilidade à erosão adotou-se a classificação proposta por Galdino et al. (2003) (Tabela $1)$.

Tabela 01: Suscetibilidade do solo a erosão

\begin{tabular}{cc}
\hline Perda de Solo $\left(\mathrm{t} \mathrm{ha}^{1}\right.$ ano $\left.^{-1}\right)$ & Grau de Erosão \\
\hline$<10$ & Baixa \\
$10-50$ & Moderada \\
$50-200$ & Alta \\
$>200$ & Muito Alta \\
\hline Fonte: Galdino et al. (2003)
\end{tabular}

\subsection{Transporte Difuso de Sedimento}

A USLE superestima a perda de solo, uma vez que fornece a produção bruta de sedimentos ou solo, não considerando a produção difusa. Em vista disso, na aplicação desta equação às bacias hidrográficas, deve-se levar-se em consideração o conceito de taxa de entrega de sedimentos (Sediment Delivery Ratio - SDR, MORRIS; FAN, 1998) (Eq. 4).

$\log _{10}(S R D)=2,943-0,824 \cdot \log _{10}\left(L_{m} / F_{r}\right)$

em que: $L_{m}=$ comprimento máximo, em linha reta, medido paralelamente ao curso d'água; $F_{r}=$ diferença entre a cota média do divisor da bacia e a cota do exutório.

A quantidade de sedimento que atinge o reservatório $M_{E}(t)$ proveniente da erosão localizada na bacia foi calculada pela Eq. 5 . 


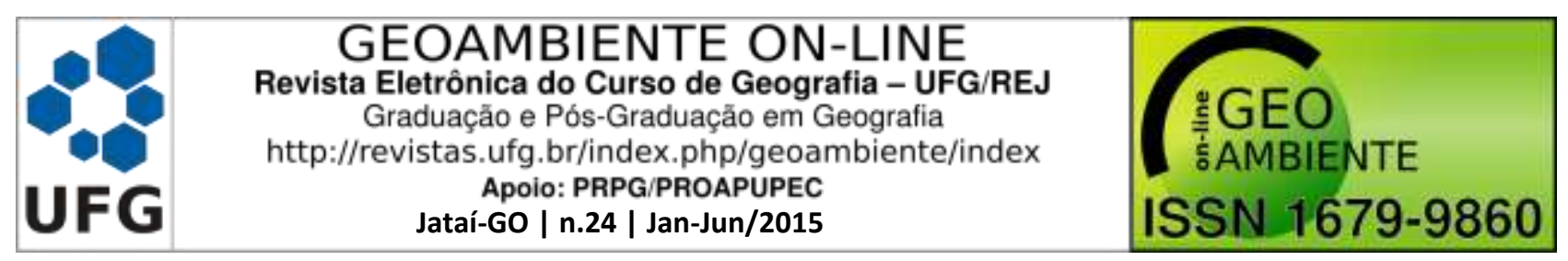

$M_{E}=E_{L} \cdot A \cdot S D R$

em que: $E_{L}=$ massa erodida localmente por unidade de área $\left(\mathrm{t} \mathrm{ha}^{-1}\right) ; A=$ área da bacia hidrográfica (ha); $S D R=$ percentual do sedimento erodido que chega ao reservatório.

O comprimento máximo em linha reta, medido paralelamente ao curso d'água $\left(\mathrm{L}_{\mathrm{m}}\right)$, foi determinado com auxilio do software ArcGis 9.3, e encontrado um valor de 8,9 km. A diferença entre a cota média do divisor da bacia e a cota do exutório foi extraída com os dados de altitudes de todos os pixéls do divisor, sendo a cota mínima como a altitude do pixel do exutório da bacia (pixel de menor altitude) e a cota média como a altitude média de todos os pixéls do divisor, com isso obteve-se o Fr de 47,3 m. Desse modo, o valor de SDR foi na ordem de $11,69 \%$.

\section{10 Assoreamento}

A massa assoreada foi determinada pela Eq. 6. Para tanto, o índice de retenção de sedimentos foi estabelecido através da curva de Brune, sendo o valor do mesmo de $95 \%$.

$M_{\text {ass }}=\eta \cdot M_{E}$

em que: $M_{\text {ass }}=$ massa assoreada $(\mathrm{t}) ; \eta=$ índice de retenção de sedimentos $(\%) ; M_{E}=$ quantidade de sedimento que atinge um dreno $(\mathrm{t})$.

\subsection{Redistribuição de Sedimentos no Reservatório}

Para construção das novas Curvas cota-volume, para estimativas do assoreamento 60, 100 e 200 anos após a construção do reservatório, foi aplicado o método de redistribuição de sedimentos por redução de área (MORRIS e FAN, 1998). A Curva cota-volume original do projeto do açude Marengo, utilizada para fins de verificação, foi adquirida junto a Companhia de Gestão de Recursos hídricos do Estado do Ceará (COGERH-CE, 2010).

De acordo a metodologia supracitada, selecionou-se uma curva empírica com base nas características do local, a fim de se proceder a distribuição de sedimentos no reservatorio. Ainda seguindo a metodologia, a forma do reservatorio foi do tipo II (Floodplain-foothill) e o regime de operação enquadrado foi o moderadamente rebaixado (tipo II). Ponderando-se as curvas de forma e de regime, obteve-se a curva tipo II para a distribuição de sedimentos para o reservatório em questão.

Após definida a curva característica de distribuição de sedimentos para o açude Marengo (Tipo II), realizou-se a distribuição de sedimentos no reservatório e determinou-se 


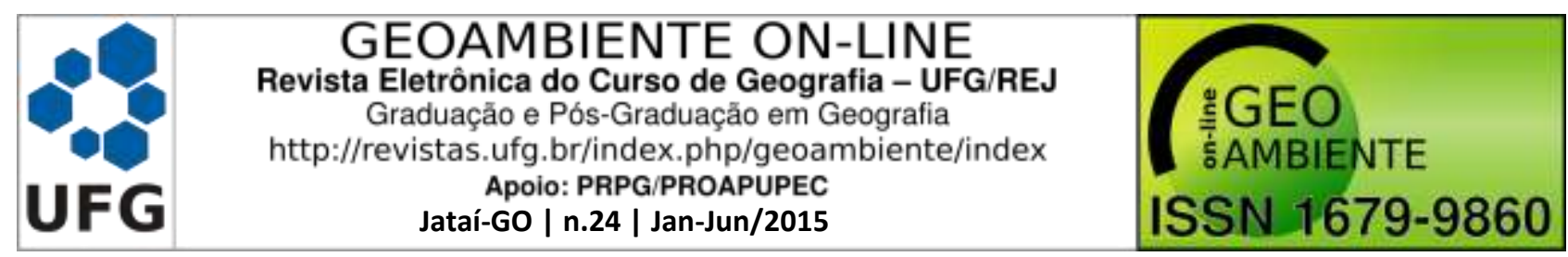

as novas Curvas cota-volume estimadas para cada cenário 60, 100 e 200 anos de assoreamento.

\section{Resultados e discussão}

\subsection{Erosividade (Fator $R$ )}

Os valores de erosividade da bacia hidrográfica do açude Marengo variaram entre 6.034 a $6.225 \mathrm{MJ} \mathrm{mm} \mathrm{ha}^{-1} \mathrm{ano}^{-1}$, apresentando valor médio de $6.141 \mathrm{MJ} \mathrm{mm} \mathrm{ha}^{-1} \mathrm{ano}^{-1}$, os quais foram próximos aos encontrados por Lopes et al. (2011) para a bacia do riacho Varjota no semiárido do Ceará de $6.328 \mathrm{MJ} \mathrm{mm} \mathrm{ha}^{-1}$ ano $^{-1}$. Ainda no semiárido do Ceará, Santos et al. (2011) encontrou valores de erosividade de $5.716 \mathrm{MJ} \mathrm{mm} \mathrm{ha}^{-1} \mathrm{ano}^{-1}$. Albuquerque et al. (2005), Farinasso et al. (2006) e Aquino et al. (2006) encontraram 4.928; 4.250 e $5.153 \mathrm{MJ}$ $\mathrm{mm} \mathrm{ha}^{-1}$ ano $^{-1}$, respectivamente, para regiões semiáridas do Nordeste brasileiro.

De maneira geral a bacia do Marengo apresenta baixa variabilidade espacial da erosividade da chuva, característica esta possivelmente atribuída ao tamanho da área em estudo 74,6 km², semelhantes aos resultados observados por Lopes et al. (2011) na bacia hidrográfica do riacho Varjota, Ceará, que apresenta uma área de $70,73 \mathrm{~km}^{2}$. Bacias hidrográficas com áreas menores tornam possível uma maior uniformidade da distribuição das chuvas, pois a probabilidade de ocorrência de chuvas em toda a área é mais significativa.

\subsection{Erodibilidade (Fator $\mathrm{K}$ )}

Observou-se na bacia de estudo a presença do solo classificado como Bruno Não Cálcico (Tipo NC) em toda a sua extensão. O valor de K atribuído para este solo foi de $0,036 \mathrm{t}$ $\mathrm{h} \mathrm{MJ}^{-1} \mathrm{~mm}^{-1}$, portanto, um solo de erodibilidade moderada, de acordo com a classificação estabelecida por Foster et al. (1981).

\subsection{Declividade e Comprimento da Rampa (Fator LS)}

A bacia em estudo apresenta relevo suave a ondulado, predominando a classe de declive variando de 0 a $5 \%$ em mais de $90 \%$ da área. Quanto ao fator LS, observa-se que o valor é baixo em praticamente toda a bacia, uma vez que o comprimento de vertente e as declividades são reduzidos. Sendo que em pouco mais de $95 \%$ da bacia apresenta valores de LS menores do que 5, próximos a resultados encontrados por Irvem et al. (2007) para a bacia do rio Seyhan na Turquia, onde observaram que 83,27 \% dos valores de LS menores do que 5. Por outro lado, onde há convergência de fluxo (vertentes côncavas), bem como altas 


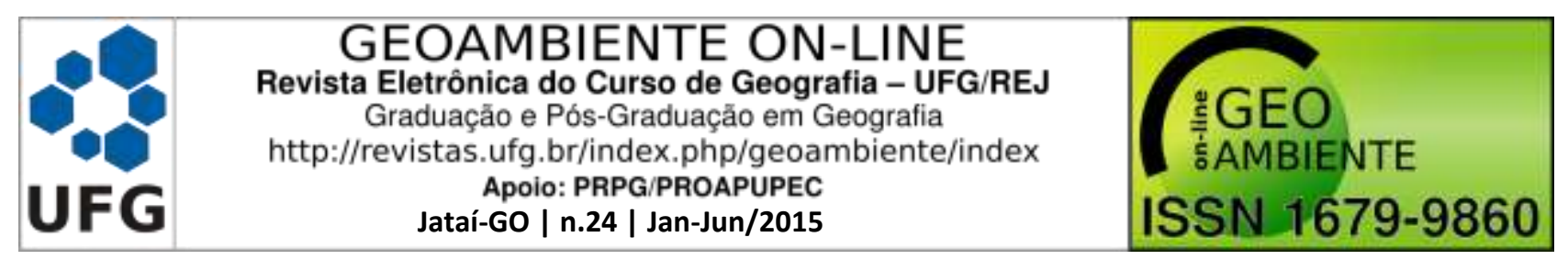

declividades, o valor de LS tende a ser elevado (Figura 10), apresentando em 4,7\% da área valores de LS superiores a 5.

\subsection{Cobertura do Solo (Fator C)}

Observa-se que a classe predominante na bacia do açude Marengo é a de vegetação rala correspondendo a 74,68\% da área. A segunda classe mais expressiva é aquela que identifica a vegetação densa, a qual abrange 13,34\% da área total. A terceira classe mais expressiva foi a de solo descoberto, correspondendo a 9,92\% da área da bacia. A última classe, expressa pelos corpos hídricos, representa 2,06\%. Lopes et al. (2011) estudando a bacia do riacho Varjota, observou percentuais bem próximo dos observados nesse estudo, verificando que a classe predominante é a de vegetação rala correspondendo a $72 \%$, seguido da vegetação intensa com $21,5 \%$, solo descoberto com $5,75 \%$ e corpos hídricos com menos de $1 \%$.

\subsection{Erosão Localizada $\left(E_{L}\right)$}

A Figura 2 apresenta o mapa da espacialização da erosão localizada para a bacia do açude Marengo. Verifica-se que a perda de solo, em 52,43\% da área apresenta valor inferior a $10 \mathrm{t} \mathrm{ha}^{-1} \mathrm{ano}^{-1}$, o que corresponde às áreas mais planas e/ou vegetadas. Aquino et al. (2007) observou que aproximadamente $80 \%$ da área do município de Iguatu, apresenta perdas compreendidas entre 0 e $10 \mathrm{t} \mathrm{ha}^{-1}$ ano $^{-1}$, sendo classificada como de baixa perda de solo. Observa-se, para a bacia em estudo, que em quase $70 \%$ da área apresentou perdas de solos abaixo de $50 \mathrm{t} \mathrm{ha}^{-1} \mathrm{ano}^{-1}$, sendo esta característica influenciada pelo relevo, visto que a bacia apresenta relevo suave a suave ondulado em mais de 90\% da área total. Irvem et al. (2007) observou que para bacia do rio Seyhan na Turquia, um pouco mais que $90 \%$ da área apresentava perda de solo moderada, com valores inferiores a $50 \mathrm{t} \mathrm{ha}^{-1} \mathrm{ano}^{-1}$. Observa-se ainda, que a perda de solo em $23,98 \%$ da área em estudo apresenta valor entre 50 e $200 \mathrm{t} \mathrm{ha}^{-1}$ ano $^{-1}$; e, apenas $7,1 \%$ da área total, apresentam valor maior que $200 \mathrm{t} \mathrm{ha}^{-1} \mathrm{ano}^{-1}$.

Pode-se verificar que as maiores perdas de solo estimadas estão nas linhas de drenagens dos riachos, devido as maiores declividades, e também nas regiões mais degradadas. Os valores resultantes do mapa de perdas de solo foram enquadrados na classificação proposta por Galdino et al. (2003). De maneira geral, a maior parte da bacia foi enquadrada nas classes de baixo e moderado grau de erosão. Sendo que em torno de $30 \%$ da área da bacia pertence às classes de alto e muito alto grau de erosão, que corresponde justamente nas áreas próximo da rede de drenagem e as regiões degradadas. Corroborando 


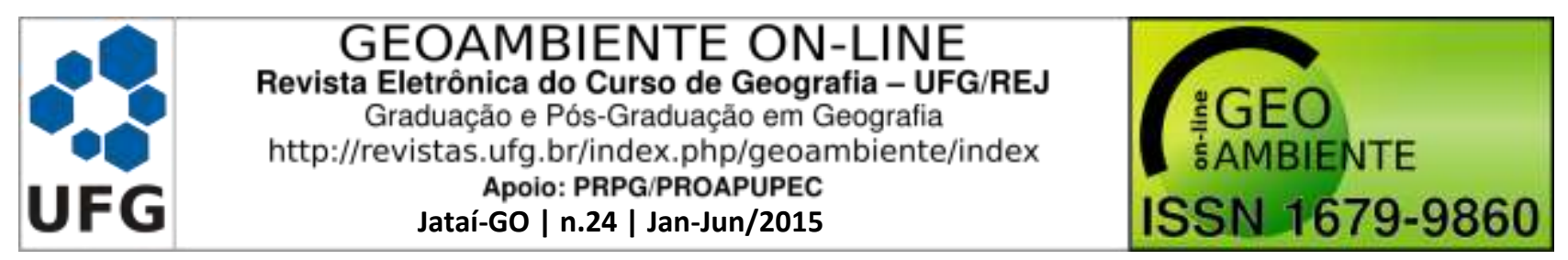

com assertivas encontrados por Lopes et al. (2011) que observou alta susceptibilidade associada ao solo descoberto e ao fator topográfico.

Figura 02: Erosão localizada em $\mathrm{t} \mathrm{ha}^{-1}$ ano $^{-1}$ para bacia do açude Marengo, Ceará

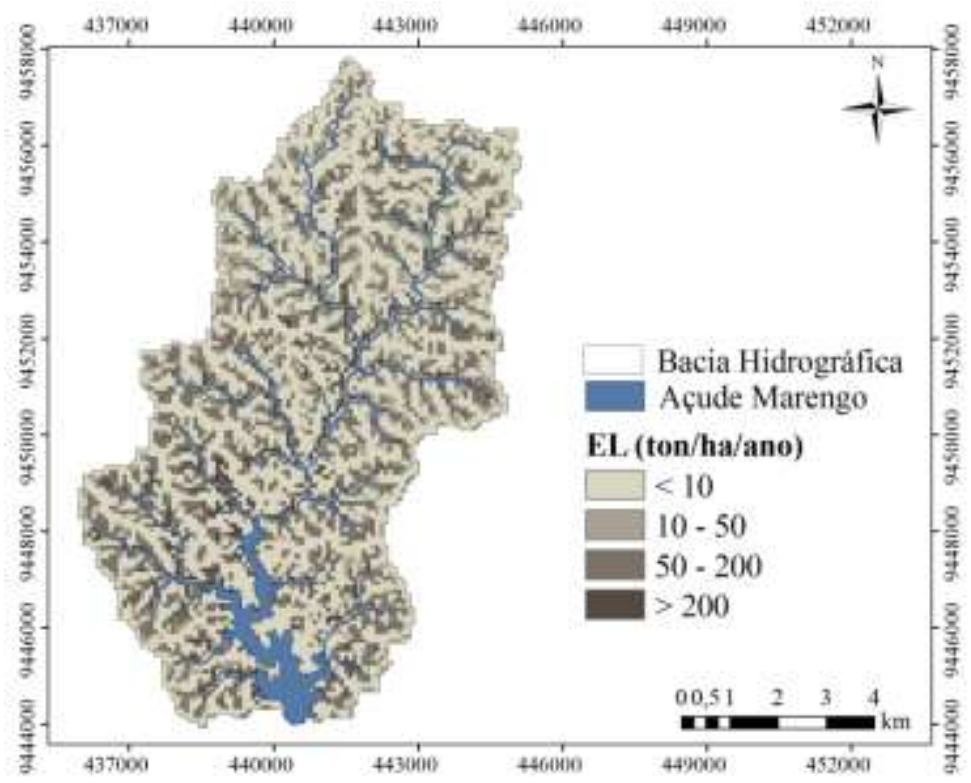

Fonte: Produção do próprio autor

\subsection{Assoreamento}

Os valores de produção de sedimentos, massa e volume assoreado médio encontrado para o açude Marengo podem ser visualizados na Tabela 2. A simulação realizada com o modelo USLE associado ao SIG indicou uma erosão localizada média anual de 333.647,73 t $\mathrm{ano}^{-1}$, o que, com um SDR de 11,69\% gera uma produção de sedimentos média anual para o açude Marengo da ordem de 38.991,68 $\mathrm{t} \mathrm{ano}^{-1}$. Sendo a área da bacia hidrográfica do açude $74,6 \mathrm{~km}^{2}$ a produção de sedimentos média por área é da ordem de 5,22 $\mathrm{t} \mathrm{ha}^{-1} \mathrm{ano}^{-1}$. Toledo et al. (2010) com o uso do modelo USLE indicou, para a bacia hidrográfica do Alto Jaguaribe, Ceará, que possui uma área total de $26.900 \mathrm{~km}^{2}$, uma produção de sedimento média por área da ordem 3,65 tha hao $^{-1}$. Os resultados obtidos neste estudo, também são compatíveis com a simulação realizada por Medeiros et al. (2011), onde o mesmo estudando o padrão espacial da produção de sedimento na bacia hidrográfica do açude do Benguê, que fica aninhada com a bacia do Alto Jaguaribe, encontrou uma produção 4,6 t ha ${ }^{-1} \mathrm{ano}^{-1}$. Araújo (2003) encontrou valores médios de 4,0 $\mathrm{t} \mathrm{ha}^{-1}$ ano $^{-1}$ em bacias do semiárido cearense.

Tabela 02: Valores de erosão localizada, produção de sedimentos, massa e volume assoreado médio e para os cenários estimados de 60, 100, 200 anos para o açude Marengo, Ceará 


\begin{tabular}{|c|c|c|}
\hline $\begin{array}{c}\text { GEOAMBIENTE ON-LINE } \\
\text { Revista Eletrônica do Curso de Geografia - UFG/REJ } \\
\text { Graduaçăo e Pós-Graduaçăo em Geografia } \\
\text { http://revistas.ufg.br/index.php/geoambiente/index } \\
\text { Apoio: PRPG/PROAPUPEC } \\
\text { Jataí-GO | n.24 | Jan-Jun/2015 }\end{array}$ & $\begin{array}{l}\text { sGE } \\
\text { ISSN }\end{array}$ & $\begin{array}{l}\text { NTE } \\
79-9860\end{array}$ \\
\hline Características & Unidades & Valores \\
\hline Erosão Localizada (Média Anual para Bacia do Marengo) & $\left(\right.$ t.ano $\left.^{-1}\right)$ & $333.647,73$ \\
\hline Peso Específico Aparente Seco & $\left(\mathrm{t} . \mathrm{m}^{-3}\right)$ & 1,30 \\
\hline SDR & $\%$ & $11,69 \%$ \\
\hline Produção de Sedimento (Média Anual para Bacia do Marengo) & $\left(\right.$ t.ano $\left.^{-1}\right)$ & $38.991,68$ \\
\hline Índice de Retenção de Sedimentos & $\%$ & $95 \%$ \\
\hline Massa Assoreada (Média Anual para Bacia do Marengo) & $\left(\right.$ t.ano $\left.{ }^{-1}\right)$ & $37.042,10$ \\
\hline Volume Assoreado (Média Anual para Bacia do Marengo) & $\left(\mathrm{m}^{3} \cdot \mathrm{ano}^{-1}\right)$ & $28.493,92$ \\
\hline Capacidade de Armazenamento & $\left(\mathrm{hm}^{3}\right)$ & 18,50 \\
\hline Taxa Assoreada por Ano & $\%$ & $0,15 \%$ \\
\hline Volume Assoreado Medido em 60 anos (Batimetria) & $\left(\mathrm{hm}^{3}\right)$ & 1,03 \\
\hline Volume Assoreado Estimado em 60 anos & $\left(\mathrm{m}^{3}\right)$ & 1,71 \\
\hline Volume Assoreado Estimado em 100 anos & $\left(\mathrm{m}^{3}\right)$ & 2,85 \\
\hline Volume Assoreado Estimado em 200 anos & $\left(\mathrm{m}^{3}\right)$ & 5,70 \\
\hline
\end{tabular}

Considerando um índice de retenção de sedimentos de 95\%, a massa assoreada média anual do reservatório foi de 37.042,10 $\mathrm{t} \mathrm{ano}^{-1}$ (Tabela 1). Admitindo um peso específico aparente seco de $1,3 \mathrm{t} \mathrm{m}^{-3}$ isso gera um o volume assoreado médio anual do reservatório de $0,028 \mathrm{hm}^{3} \mathrm{ano}^{-1}$, produzindo uma taxa de assoreamento anual aparentemente moderada da ordem de 0,15\%. Resultados semelhantes foram observados por Araújo (2003) para o reservatório Acarape do Meio, Ceará, que observou uma taxa média de 0,106\% ao ano, já para o reservatório Várzea do Boi, Ceará, ocorreu uma redução da capacidade de armazenamento a uma taxa relativamente alta de $0,24 \%$ ao ano. Essa baixa taxa de assoreamento observada para bacia em estudo deve-se ao fato de que quase $70 \%$ da bacia estudada apresentou um grau moderado de erosão, em decorrência ao relevo suave a ondulado em mais de $90 \%$ da área total, bem como das áreas vegetadas presentes na bacia.

Ainda dentre os valores apresentados na Tabela 1, é possível verificar uma redução na capacidade de acumulação do reservatório de $1,03 \mathrm{hm}^{3}$, medida a partir da batimetria para um período 60 anos após a construção do reservatório. Com aplicação do modelo, estimou-se no mesmo período de 60 anos uma redução de $1,71 \mathrm{hm}^{3}$ da capacidade de acumulação. Essa superestimativa do modelo USLE+SIG deve-se, em parte, a não consideração dos sedimentos retidos nos açudes presentes na bacia hidrográfica a montante do açude Marengo, estes são responsáveis pela retenção de parte dos sedimentos que porventura poderiam vir a ser depositados no reservatório (LIMA NETO et al., 2011). Extrapolando a simulação para cenários de 100 e 200 anos de assoreamento, o volume perdido seriam, respectivamente, 2,85 $\mathrm{hm}^{3}$ e $5,70 \mathrm{hm}^{3}$. 


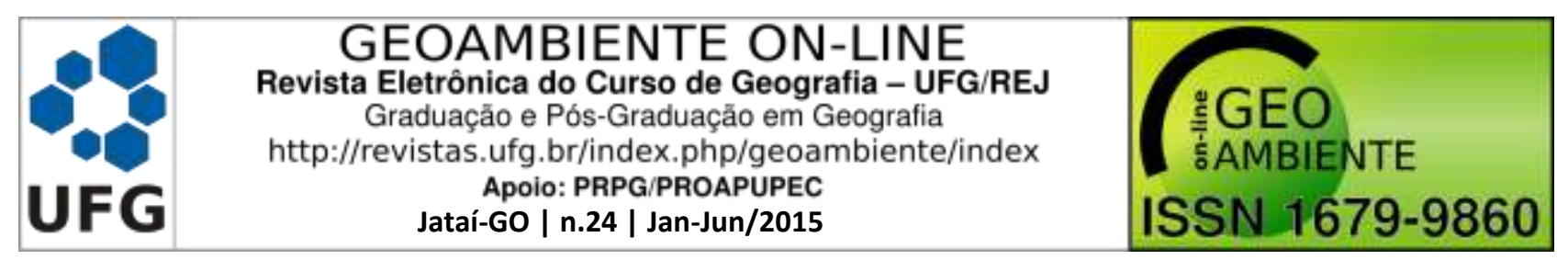

Além do impacto do assoreamento na capacidade de acumulação, outra análise de importância relevante é a avaliação do impacto do assoreamento na disponibilidade hídrica do reservatório. Para tal, Araújo et al. (2006), ao estudarem a perda de volume de reservatórios pela deposição de sedimentos associado à disponibilidade de água em reservatórios do semiárido cearense, concluíram que o assoreamento dos reservatórios tiveram maior impacto na vazão regularizável do que na capacidade de armazenamento.

Para verificação da robustez do modelo aplicado, USLE associado ao SIG, verifica-se que a Curva cota-volume medida a partir da batimetria, 60 anos após a construção do reservatório, está próxima da curva estimada pelo modelo no mesmo período de tempo (Figura 3). No entanto, após a distribuição dos sedimentos, a curva medida pela batimetria em determinadas cotas apresenta volumes maiores do que a estimada, em outras, o volume da curva estimada é superior à medida.

O impacto do assoreamento do reservatório na curva cota-volume para os cenários de 60, 100 e 200 anos de assoreamento também pode ser observado. Verifica-se o impacto do assoreamento diretamente nos volumes de cada cota, por exemplo, para a cota $290 \mathrm{~m}$ teríamos para o projeto original um volume de $4,81 \mathrm{hm}^{3}$, já para os cenários de 60, 100 e 200 anos de assoreamento os volumes para esta mesma cota seriam de 3,72; 3,11 e 1,48 $\mathrm{hm}^{3}$, respectivamente.

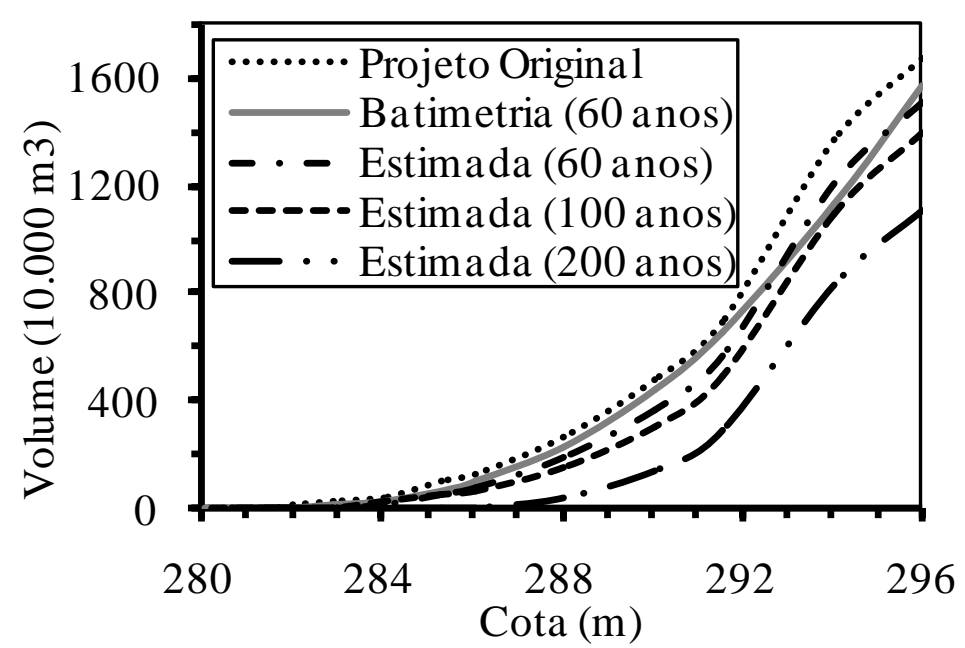

Figura 3 - Curvas cota-volume medida 60 anos após a construção e estimadas para 60, 100 e 200 anos de assoreamento do açude Marengo.

\section{Conclusão}




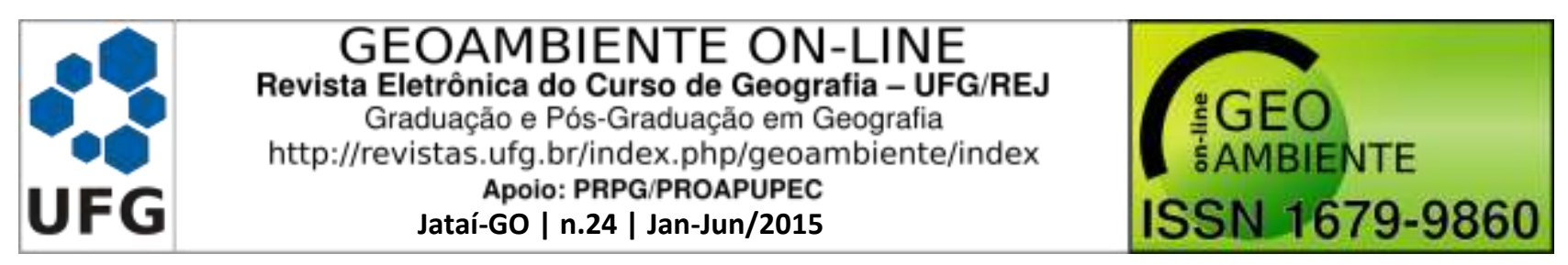

i) A perda de solo espacializada pelo modelo USLE associado ao SIG foi em quase 70\% da bacia estudada em um grau moderado de erosão.

ii) A taxa de redução da capacidade de armazenamento mostrou-se moderada, com taxa anual de $0,15 \%$.

iii) A simulação da erosão pelo modelo USLE atrelada a uma metodologia de produção de sedimentos e distribuição dentro do reservatório, permitiu uma coerente aproximação aos valores medidos.

iv) Extrapolando a simulação para cenários de 100 e 200 anos de assoreamento, o volume perdido seriam, respectivamente, $2,85 \mathrm{hm}^{3}$ e $5,70 \mathrm{hm}^{3}$.

\section{Referências}

ALBUQUERQUE, A.W.; FILHO, G.M.; SANTOS, J.R.; COSTA, J.P.V.; SOUZA, J.L. Determinação de fatores da equação universal de perda de solo em Sumé, PB. Revista Brasileira de Engenharia Agrícola e Ambiental, v. 9, n. 2, p. 153-160, 2005.

AQUINO, C.M.S.; OLIVEIRA, J.G.B.; SALES, M.C.L. Estimativa da erosividade das chuvas (R) nas terras secas do Estado do Piauí. Revista Ciência Agronômica, v. 37, n. 3, p. 287-291, 2006.

ARAÚJO, J.C. Assoreamento em reservatórios do semi-árido: modelagem e validação. Revista Brasileira de Recursos Hídricos, v. 8, n. 2, p. 39-56, 2003.

ARAÚJO, J.C.; MOLINAS, P.A.; JOCA, E.L.L.; BARBOSA, C.P.; BEMFEITO, C.J.S.;

BELO, P.S.C . Custo de disponibilização e distribuição da água por diversas fontes no Ceará. Revista. Econômica do Nordeste, v. 36, 2005.

ARAÚJO, J.C.; GÜNTNER, A.; BRONSTERT, A. Loss of reservoir volume by sediment deposition and its impact on water availability in semiarid Brazil. Hydrological Sciences Journal des Sciences Hydrologiques, v. 51, n. 1, 2006.

BERTONI, J.; LOMBARDI NETO, F. Conservação do Solo. São Paulo: Ícone, 1990. 335p.

CHAIR, L.Z. Soil erosion modeling using the revised universal soil loss equation (rusle) in a drainage basin in eastern Mexico. 2005. Disponível em: <http://www.utexas.edu/depts/grg/hudson/grg360g/EGIS/labs_04/Lab9/lab9_soil_erosion_05. htm>. Acesso em: 07 junho de 2010.

FARINASSO, M.; CARVALHO JÚNIOR, A.O.; GUIMARÃES, R.F.; GOMES, R.A.T.; RAMOS, V.M. Avaliação qualitativa do potencial de erosão laminar em grandes áreas por meio da EUPS - Equação Universal de Perdas de Solos - utilizando novas metodologias em 


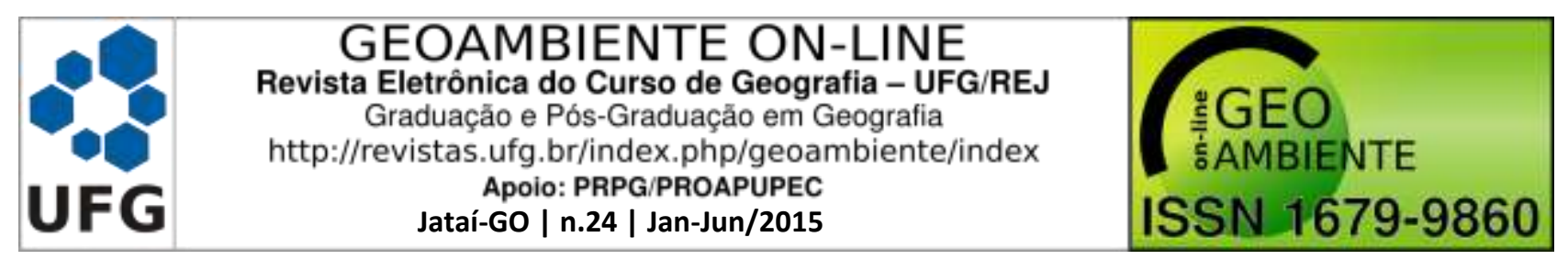

SIG para os cálculos dos seus fatores na região do Alto Parnaíba - PI-MA. Revista Brasileira de Geomorfologia, v. 7, n.2, p. 73-85, 2006.

FOSTER, G.R.; MCCOOL, D.K.; RENATO, K.G.; MOLDENHAUER, W.C. Conservation of the Universal Soil Loss Equation the SI metric units. Journal of Soil and Water Conservation, v. 36, p. 355-359, 1981.

FUJIHARA, A.K. Predição de erosão e capacidade de uso do solo numa microbacia do Oeste Paulista com suporte em geoprocessamento. 2002. 136 f. Dissertação de Mestrado. Escola Superior de Agricultura Luiz de Queiroz, Piracicaba.

GALDINO, S.; VIEIRA, L.M.; SORIANO, B.M.A. Perdas de solo na bacia do alto Taquari. Corumbá. Corumbá, Embrapa Pantanal. 2003. 40p. (Boletim técnico, 52).

IRVEM, A.; TOPALOGLU, F.; UYGUR, V. Estimating spatial distribution of soil loss over Seyhan River Basin in Turkey. Journal of Hydrology, v. 336, p. 30 - 37, 2007.

LIMA NETO, I.E.; WIEGAND, M.C.; ARAÚJO, J.C. Sediment redistribution due to a dense reservoir network in a large semiarid Brazilian basin. Hydrological Sciences Journal, v. 56, p. $319-333,2011$.

LOPES, F.B.; ANDRADE, E.M.; TEIXEIRA, A.S.; CAITANO, R.F.; CHAVES, L.C.G. Uso de geoprocessamento na estimativa da perda de solo em microbacia hidrográfica do semiárido brasileiro. Revista Agro@mbiente On-line, v. 5, n. 2, p. 88 - 96, 2011.

MAIA, A.G.; VILLELA, S.M. A necessidade da consideração do processo de assoreamento no planejamento e operação de reservatórios. Revista Brasileira de Recursos Hídricos, v. 11, n. 2, p. $187-193,2006$.

MEDEIROS, P.H.A.; GUNTNER, A.; FRANCKE, T.; MAMEDE, G.L.; ARAUJO, J.C. Modelling spatio-temporal patterns of sediment yield and connectivity in a semi-arid catchment with the WASA-SED model. Hydrological Sciences Journal, v. 55, p. 636 - 648, 2010 .

MORRIS, G.L.; FAN, J. Reservoir Sedimentation Handbook. New York: McGraw-Hill Book Co., 1998. $805 \mathrm{p}$.

SANTOS, J.C.N.; PALÁCIO, H.A.Q.; ANDRADE, E.M.; MEIRELES, A.C.M.; ARAÚJO NETO, J.R. Runoff, soil loss and soil nutrients in semiarid areas of uncultivated. Revista Ciência Agronômica, v. 42, n. 3, p. 813 - 820, 2011.

SERGIO, J.; COSTA, C.A.G.; TEIXEIRA, A.S.; ORTEGA, E. Aplicação da USLE e SIG na caracterização de três micro bacias hidrográficas no Brasil. Revista Acadêmica: Ciências Agrárias e Ambientais, v. 6, n. 2, p. 213 - 221, 2008. 


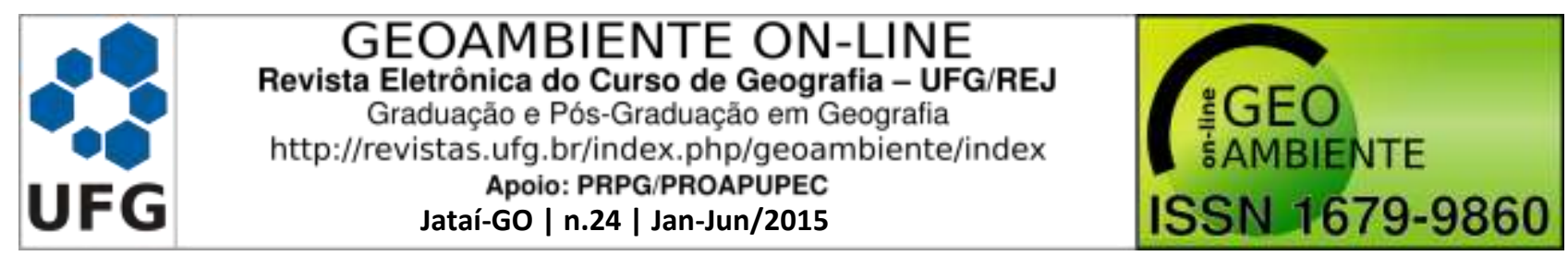

SILVA, J.R.C. Perdas de solo e produção de sedimentos. 1978. 125 f. Dissertação de Mestrado. Escola Superior de Agricultura “Luiz de Queiroz”, Piracicaba TOLEDO, C.E.; SANTOS, A.T.; ARAÚJO, J.C.; ALMEIDA, C.R.; LOPES, J.W.B. Produção espacial de sedimento aplicando a USLE e o SIG em uma bacia hidrográfica semiárida. In: Encontro Nacional de Engenharia de Sedimentos, 9., 2010, Brasília. Anais... Brasília: ABRH. 1 CD.

WISCHMEIER, W.H.; SMITH, D.D. Predicting rainfall erosion losses: a guide to conservation planning. In: Agriculture handbook (537). Washington, United States Department of Agriculture. 1978. 